\title{
Enhancement of encapsulation efficiency of nanoemulsion-containing aripiprazole for the treatment of schizophrenia using mixture experimental design
}

\author{
This article was published in the following Dove Press journal: \\ International Journal of Nanomedicine \\ 13 October 2015 \\ Number of times this article has been viewed
}

Hamid Reza Fard Masoumi

Mahiran Basri

Wan Sarah Samiun

Zahra Izadiyan

Chaw Jiang Lim

Nanodelivery Group, Department of Chemistry, Faculty of Science,

Universiti Putra Malaysia, Serdang,

Selangor, Malaysia
Correspondence: Hamid Reza Fard Masoumi; Mahiran Basri

Nanodelivery Group, Department of

Chemistry, Faculty of Science, Universiti

Putra Malaysia, 43400 Serdang, Selangor,

Malaysia

Tel +603894677266

Fax +60389432508

Email fardmasoumi@upm.edu.my;

mahiran@upm.edu.my
Abstract: Aripiprazole is considered as a third-generation antipsychotic drug with excellent therapeutic efficacy in controlling schizophrenia symptoms and was the first atypical antipsychotic agent to be approved by the US Food and Drug Administration. Formulation of nanoemulsion-containing aripiprazole was carried out using high shear and high pressure homogenizers. Mixture experimental design was selected to optimize the composition of nanoemulsion. A very small droplet size of emulsion can provide an effective encapsulation for delivery system in the body. The effects of palm kernel oil ester (3-6 wt \%), lecithin (2-3 wt \%), Tween $80(0.5-1 \mathrm{wt} \%)$, glycerol (1.5-3 wt \%), and water (87-93 wt \%) on the droplet size of aripiprazole nanoemulsions were investigated. The mathematical model showed that the optimum formulation for preparation of aripiprazole nanoemulsion having the desirable criteria was $3.00 \%$ of palm kernel oil ester, $2.00 \%$ of lecithin, $1.00 \%$ of Tween $80,2.25 \%$ of glycerol, and $91.75 \%$ of water. Under optimum formulation, the corresponding predicted response value for droplet size was $64.24 \mathrm{~nm}$, which showed an excellent agreement with the actual value $(62.23 \mathrm{~nm})$ with residual standard error $<3.2 \%$.

Keywords: schizoaffective disorder, antipsychotic drug, bipolar I disorder, D-optimal mixture design, optimization formulation

\section{Introduction}

Schizophrenia is a serious psychiatric condition that affects $\sim 1 \%$ of worldwide population. ${ }^{1}$ This mental illness is characterized by positive symptoms (eg, hallucinations, delusions, and deranged thoughts), negative symptoms (eg, loss of motivation, restricted emotional experience, and poverty of speech), and cognitive impairment. In recent years, a medication (aripiprazole) has received growing attention for the treatment of schizophrenia. Aripiprazole has been demonstrated to be effective for the treatment of positive and negative symptoms in the schizophrenia or schizoaffective disorder for acute and long-term treatment in adults at doses of $10-30 \mathrm{mg} / \mathrm{d}^{2-6}$

Aripiprazole (Abilify ${ }^{\circledR}$ ) is an atypical antipsychotic drug with D2 partial agonist properties and high D2 receptor affinity. This partial agonist can reduce D2 hyperactivation in the mesolimbic pathway, thus alleviating positive symptoms of schizophrenia, but provide enough D2 receptor stimulation in the mesocortical pathway and the nigrostriatal pathway to prevent, respectively, negative symptoms and extrapyramidal side effects. ${ }^{7-10}$ Initially developed for the treatment of schizophrenia, it is also used to treat bipolar I disorder (acute treatment of manic and mixed episodes and maintenance 
treatment of bipolar I disorder), major depressive disorder (as an adjunctive therapy to antidepressant), and irritability associated with autistic disorder. Finally, aripiprazole injection is indicated for the acute treatment of agitation associated with schizophrenia or bipolar disorder. ${ }^{11}$

Despite these vast gains, aripiprazole is insoluble in water, which makes it very challenging to incorporate it in pharmaceutical products. For enhancing the dissolution rate of poorly water soluble molecule, the surface area is purposely increased by reducing the droplet size of drug molecule. Increasing the surface area can affect the performance extremely. ${ }^{12}$ An alternative route of application can be considered where oil as a biocompatible carrier for aripiprazole in the composition of a nanoemulsion. This is able to improve the solubility as well as bioavailability of aripiprazole.

A nanoemulsion-based aripiprazole carrier could improve the solubility of the drug in the dispersed phase and drug penetration into the blood-brain barrier and target cells due to its extremely small size. Thus, a smaller dose of aripiprazole is preferred to reduce the side effects. In this context, the development of new drug nanodelivery systems to increase drug bioavailability and reduce adverse effects has been claimed as a good option.

The study of the influence of the mixture composition in nanoemulsion formulation should be addressed by experimental design techniques for mixtures, also known as mixture experimental design (MED). Besides helping to maximize the amount of acquired information and minimize the number of experiments to be carried out, these designs allow characterization and identification of synergistic and antagonistic interaction effects between different components. Nevertheless, some studies revealed on the study of formulation composition through these techniques in recent years $^{13-16}$ that formulation investigations would be more suitable if these techniques were utilized more frequently. ${ }^{17}$

In this study, a MED was carried out to formulate nanoemulsion compounds containing aripiprazole by varying five components of mixture composition. Droplet size of nanoemulsions as a response was evaluated and statistical mixture models were developed. The measured response has to be minimized in order to produce a product of desired characteristics. In this case, the response comprises the droplet size $(<200 \mathrm{~nm})$.

\section{Material and methods \\ Materials}

Palm kernel oil esters (PKOEs) were synthesized in our laboratory by lipase-catalyzed transesterification of palm kernel oil and oleyl alcohol. ${ }^{18}$ Pure soy bean lecithin (Lipoid S75) was purchased from Lipoid GmbH (Ludwigshafen, Germany). Glycerol was purchased from JT Baker (Philipsburg, NJ, USA). Polysorbate 80 (Tween 80) was obtained from Fluka, Sigma-Aldrich Co. (St Louis, MO, USA). Aripiprazole was purchased from Laboratory and Scientific Enterprise, Malaysia. Water was deionized using a Milli-Q filtration system, EMD Millipore (Billerica, MA, USA).

\section{Determination of the loading capacity of aripiprazole in oil}

To evaluate the loading capacity of aripiprazole dispersions based on PKOEs as oil, poorly water soluble drug was added in various concentrations to the basic compositions. The composition of the drug-loaded systems and the observed instability phenomena were investigated. Different amounts of drug were added into the oil-containing lecithin (3\%). The solutions were kept under moderate magnetic stirring for 24 hours to reach equilibrium. The samples were then centrifuged at 4,500 rpm for 15 minutes. The best amount of drug was observed as $0.1 \%$ in the composition formulation.

\section{Preparation of formulation of the emulsion using low shear rate emulsification}

Emulsions were prepared via low shear rate stirring emulsification using an overhead stirrer (IKA ${ }^{\circledR}$ RW20 Digital, Nara, Japan) at 300-305 rpm. Aripiprazole (0.1\%) was dissolved in the oil phase, which is PKOEs $(3.0 \%-6.0 \%)$ containing lecithin $(2.0 \%-3.0 \%)$ as the emulsifier. Tween 80 $(0.5 \%-1.0 \%)$ was then added into the oil phase as a coemulsifier after the aripiprazole was completely dissolved. The oil phase was added dropwise into the aqueous phase consisting of glycerol and was continuously stirred to form a coarse emulsion. The mixing of emulsion was carried out with a shear rate of 300-305 rpm for 3 hours.

\section{Preparation of nanoemulsion using high shear and high pressure homogenization}

The prepared emulsion by low shear rate emulsification was homogenized using a high shear homogenizer (Kinematica AG, Luzern, Switzerland) at high speed (3,500 rpm) for 15 minutes. The samples were further homogenized using a high pressure homogenizer 1,000 psi for 14 cycles. The final products were put into sample bottles.

\section{Stability study}

Freshly prepared samples were put in a container, and it was stored in the refrigerator at $\pm 5^{\circ} \mathrm{C}$ for 9 months. To test 
the stability of the samples, the samples were centrifuged at $4,500 \mathrm{rpm}$ for 15 minutes. The samples were then observed to see whether there were any precipitates formed.

\section{Droplet size measurement}

The droplet size distribution, mean droplet diameter, $\zeta$-potential, and polydispersity index (PDI) of nanoemulsion formulations were determined using a commercial Dynamic Light Scattering instrument (Zetasizer Nano ZS; Malvern Instruments, Malvern, UK). The samples were diluted with deionized water by adding a drop of the sample into water in a cuvette. The measurement was carried out at $25^{\circ} \mathrm{C} \pm 0.5^{\circ} \mathrm{C}$. In order to demonstrate reproducibility, each experimental run was conducted in triplicate.

\section{Experimental design}

The composition is the factor of interest in an MED. The main specification of a mixture formulation is that the sum of all its components' proportions must be $=1$. Moreover, the response is supposed to depend only on the relative proportions of the components in the mixture and not on the volume of the mixture. ${ }^{19}$ In this study, a D-optimal experimental design was chosen for modeling and evaluates the effects of the five components on the droplet size of nanoemulsion. This design supplies maximum amount of acquired information from a minimum number of experiments. In addition, when the results are represented as models, an optimum composition with desirable criteria can be numerically or graphically determined.

The present work aimed to evaluate the effect of five selected components on the size and emulsification abilities of the droplets. The following five components were chosen according to the drug solubility and emulsifying ability: PKOEs $\left(\mathrm{X}_{1}\right)$, lecithin $\left(\mathrm{X}_{2}\right)$, Tween $80\left(\mathrm{X}_{3}\right)$, glycerol $\left(\mathrm{X}_{4}\right)$, and water $\left(\mathrm{X}_{5}\right)$. In this work, the minimum and the maximum molar proportions of these components were arbitrarily selected as follows: $3 \leq \mathrm{X}_{1} \leq 6 \% ; 2 \leq \mathrm{X}_{2} \leq 3 \%$; $0.5 \leq X_{3} \leq 1 \% ; 1.5 \leq X_{4} \leq 3 \% ;$ and $87 \leq X_{5} \leq 93 \%$ (Table 1$)$. Mathematically, the sum of the percentage of components

Table I Restrictions of component proportions (\%)

\begin{tabular}{lllll}
\hline Symbol & Variables & Units & \multicolumn{2}{l}{ Range (\%) } \\
\cline { 4 - 5 } & & & Lower & Higher \\
\hline$A$ & PKOEs & $w t \%$ & 3.00 & 6.00 \\
$B$ & Lecithin & $w t \%$ & 2.00 & 3.00 \\
$C$ & Tween 80 & $w t \%$ & 0.50 & 1.00 \\
$D$ & Glycerol & $w t \%$ & 1.50 & 3.00 \\
$E$ & Water & wt\% & 87.00 & 93.00 \\
\hline Abbreviation: & PKOE, palm kernel oil ester. & &
\end{tabular}

must be $=100 \%: X_{1}+X_{2}+X_{3}+X_{4}+X_{5}=100 \%$. The factor space of design is obviously not a regular simplex but a convex polyhedron due to these constraints. ${ }^{20}$ In addition, the constraints were used to the components' proportions of mixture, in order to comply with the relevant amounts of them actually utilized in commercial pharmaceutical formulations. For constructing the final model, previous experiments suggested that a nonlinear response function must be expected. Therefore, a quadratic model was selected for interpreting data results from the D-optimal experimental design as shown in the following equation:

$$
Y_{i}=\sum_{i=1}^{5} \beta_{i} x_{i}+\sum_{i=1}^{4} \sum_{i=1}^{5} \beta_{i j} x_{i} x_{j}+\mathcal{E}
$$

The coefficients $\beta_{i}$ and $\beta_{i j}$ represent the regression coefficients calculated from the experimental data by multiple regression. The generated model contained quadratic terms, which explained the nonlinear nature of responses and multiple factor terms explaining interaction effects between factors. The generated model contained quadratic terms, which explained the nonlinear nature of responses and multiple factor terms explaining interaction effects between factors.

\section{Statistical analysis}

Computational work, including experimental points designing, randomization, analysis of variance (ANOVA), finding outliers, fitting of the second-order polynomial model, optimization, and graphical representations (ternary plots), was performed using a statistical packages, Design-Expert, Version 7.0 (Stat-Ease Inc., Minneapolis, MN, USA) and Statistica, Version 12 (Statsoft Inc., Tulsa, OK, USA). The model was tested for goodness of fit correlation of determination $\left(R^{2}\right)$, and ANOVA was applied to verify the adequacy of the regression model in terms of a lack-of-fit test. ANOVA results are based on confidences level $\alpha=0.05$, and effectiveness of each variable should be determined according to its probability value ( $P$-value). So, the terms with probability $P \geq 95 \%(\alpha \leq 0.05)$ assume significance.

\section{Results and discussion} Some physicochemical properties of variables for aripiprazole-loaded nanoemulsion

PKOEs are used as one of the variables in the MED. PKOEs were selected based on their behavior in drug carrier system. PKOEs consist of relatively shorter chain esters that are potentially good carriers for the delivery of active ingredients 
into the body. ${ }^{18}$ Tween 80 as a coemulsifier provided the smallest droplet size as well as PDI. Lecithin, a natural emulsifier, which mimics the biological system in the brain either by electrostatic or by covalent binding, is known to help particles cross the blood-brain barrier. ${ }^{21}$ However, lecithin by itself was not enough to form a good nanoemulsion system. It has been reported that the usage of lecithin as an emulsifier may lead to the formation of lysoderivatives. ${ }^{22}$ The formation of lysoderivatives should be controlled to prevent hemolytic potential in the body. However, use of a coemulsifier such as Tween 80 can minimize this undesired problem. The usage of Tween 80 in pharmaceutical applications results in favorable encapsulation efficiency. ${ }^{23}$ Therefore, Tween 80 was selected as the coemulsifier in this study.

\section{Designing the experiments}

The variation in the droplet size of nanoemulsions was predicted by employing D-optimal MED as the response function of the formulation composition containing aripiprazole. The effects of five independent variables (Table 1) were investigated using D-optimal MED, and the results of 25 experiments are shown in Table 2. According to this experimental design, the experiment mixtures were prepared and determined by photon correlation spectroscopy using a Zetasizer 3000 (Malvern Instruments), which could measure droplet size between $10 \mathrm{~nm}$ and 5,000 $\mathrm{nm}$.
Using Design-Expert software Version 7.0, a quadratic model was fitted to the experimental results. The best model was fitted according to the following seven main criteria: high $F$-value, low $P$-value $(<0.05)$, insignificant lack of fit, high $R^{2}(>0.90)$, low standard deviation, a randomly scatter plot of residuals, and whether it is able to predict well the validation set. The final obtained model to predict the droplet size nanoemulsions in terms of the actual factors of mixture components can be expressed as follows:

$$
\begin{aligned}
Y= & 155.26 A+267.66 B+2007.10 C+162.98 D \\
& +84.03 E-161.72 A-2777.75 A C-73.86 A D \\
& +23.62 A E-2501.03 B C-300.65 B D-234.53 B E \\
& -2520.56 C D-2324.99 C E
\end{aligned}
$$

where $A, B, C, D$, and $E$ represent the fractions of PKOEs, lecithin, Tween 80 , glycerol, and water in $\mathrm{wt} \%$, respectively.

From Table 2, it can be seen the minimum value of droplet size first occurred in run number 15 with the value of $65.25 \mathrm{~nm}$ and also the second minimum value of droplet size occurred in run number 19 with the value of 65.55 .

Figure 1 shows the predicted droplet size values (derived from the model) versus actual droplet size values (obtained from experiments). This figure shows that the model was

\begin{tabular}{|c|c|c|c|c|c|c|c|}
\hline \multirow{2}{*}{$\begin{array}{l}\text { Run } \\
\text { number }\end{array}$} & \multirow{2}{*}{$\begin{array}{l}\text { PKOEs (A), } \\
\text { (wt\%) }\end{array}$} & \multirow{2}{*}{$\begin{array}{l}\text { Lecithin (B), } \\
\text { (wt\%) }\end{array}$} & \multirow{2}{*}{$\begin{array}{l}\text { Tween } 80(C) \text {, } \\
\text { (wt\%) }\end{array}$} & \multirow{2}{*}{$\begin{array}{l}\text { Glycerol (D), } \\
\text { (wt\%) }\end{array}$} & \multirow{2}{*}{$\begin{array}{l}\text { Water (E), } \\
\text { (wt\%) }\end{array}$} & \multicolumn{2}{|c|}{ Droplet size $(\mathrm{nm})$} \\
\hline & & & & & & Actual & Predicted \\
\hline 1 & 3.00 & 2.00 & 0.75 & 1.50 & 92.75 & 71.56 & 71.32 \\
\hline 2 & 6.00 & 2.00 & 0.50 & 2.25 & 89.25 & 124.57 & 124.46 \\
\hline 3 & 6.00 & 3.00 & 0.50 & 1.50 & 89.00 & 124.97 & 127.68 \\
\hline 4 & 6.00 & 2.00 & 1.00 & 3.00 & 88.00 & 87.62 & 87.50 \\
\hline 5 & 4.50 & 2.00 & 0.75 & 2.25 & 90.50 & 86.55 & 86.83 \\
\hline 6 & 5.25 & 2.50 & 0.625 & 1.875 & 89.75 & 103.43 & 103.29 \\
\hline 7 & 6.00 & 2.00 & 1.00 & 1.50 & 89.50 & 86.18 & 88.36 \\
\hline 8 & 3.00 & 2.50 & 0.50 & 1.50 & 92.50 & 81.35 & 81.42 \\
\hline 9 & 3.00 & 2.00 & 0.50 & 3.00 & 91.50 & 84.43 & 84.30 \\
\hline 10 & 6.00 & 3.00 & 0.50 & 1.50 & 89.00 & 130.37 & 127.68 \\
\hline II & 6.00 & 2.00 & 1.00 & 1.50 & 89.50 & 90.48 & 88.36 \\
\hline 12 & 3.00 & 2.00 & 1.00 & 2.25 & 91.75 & 66.20 & 64.24 \\
\hline 13 & 6.00 & 3.00 & 1.00 & 2.25 & 87.75 & 89.59 & 90.04 \\
\hline 14 & 3.00 & 3.00 & 0.50 & 2.25 & 91.25 & 81.39 & 81.36 \\
\hline 15 & 3.00 & 3.00 & 1.00 & 1.50 & 91.50 & 65.25 & 65.53 \\
\hline 16 & 5.25 & 2.75 & 0.875 & 2.625 & 88.50 & 89.07 & 88.38 \\
\hline 17 & 4.50 & 2.50 & 0.75 & 3.00 & 89.25 & 87.12 & 87.70 \\
\hline 18 & 4.50 & 3.00 & 1.00 & 1.50 & 90.00 & 80.26 & 79.89 \\
\hline 19 & 3.00 & 3.00 & 1.00 & 3.00 & 90.00 & 65.55 & 65.45 \\
\hline 20 & 4.50 & 2.00 & 0.50 & 1.50 & 91.50 & 106.33 & 106.27 \\
\hline
\end{tabular}
successful in capturing the correlation between the mixture components with $R^{2}$ of 0.9957 .

Table 2 Predicted and actual values of droplet size of nanoemulsions obtained from D-optimal mixture experimental design

Note: $A, B, C, D$, and $E$ represent the fractions of PKOEs, lecithin, Tween 80 , glycerol, and water in wt\%, respectively. Abbreviation: PKOE, palm kernel oil ester. 


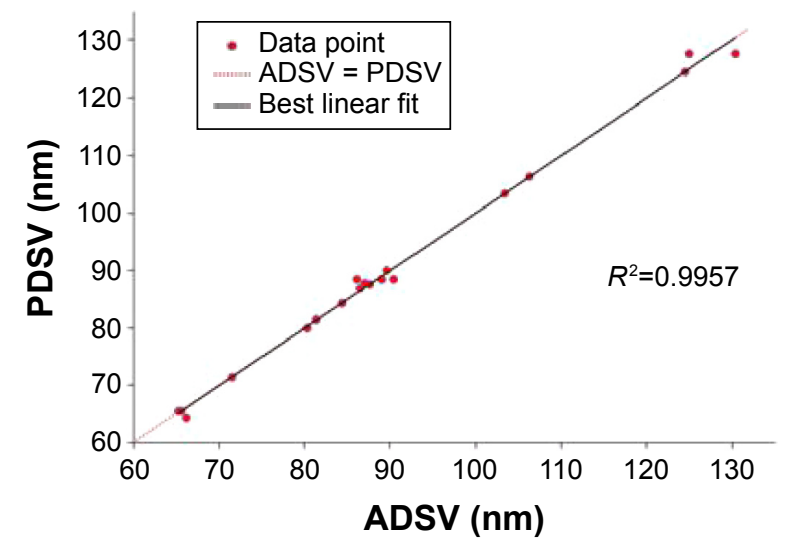

Figure I Scatter plot of predicted droplet size value (PDSV) versus actual droplet size value (ADSV) from D-optimal experimental mixture design.

\section{Analysis of variance}

Based on Table 3, the response (droplet size) was well fitted to the quadratic model with $F$-value and $P$-value of 98.65 and $<0.0001$, respectively. According to the values of linear terms in Table 3 and Equation 2, it can be said that all the linear mixture components $(A, B, C, D$, and $E$ ) were effective on the response according to their coefficients and $P$-value of linear mixture. The greatest influence on the droplet size was shown by factor $C$ (Tween 80 ).

A response was investigated regarding outliers, and it was found that all points were placed in a normal distribution.

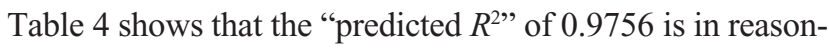
able agreement with the "adjusted $R^{2}$ " of 0.9856 . "Adequate precision" measures the signal-to-noise ratio. A ratio $>4$ is desirable. The ratio of 31.944 indicates an adequate signal. This model can be used to navigate the design space. The results

Table 3 Analysis of variance of the fitted linear/quadratic equation for droplet size of nanoemulsions

\begin{tabular}{llll}
\hline Source & \multicolumn{2}{l}{ Droplet size } & \\
\cline { 2 - 4 } & Mean square & F-value & P-value \\
\hline Model & 544.83 & 98.65 & $<0.0001$ \\
Linear mixture & $1,812.25$ & 328.15 & $<0.0001$ \\
$A B$ & 2.10 & 0.38 & 0.5601 \\
$A C$ & 18.77 & 3.40 & 0.1148 \\
$A D$ & 4.47 & 0.81 & 0.4030 \\
$A E$ & 3.47 & 0.63 & 0.4579 \\
$B C$ & 12.86 & 2.33 & 0.1778 \\
$B D$ & 6.20 & 1.12 & 0.3301 \\
$B E$ & 4.31 & 0.78 & 0.4111 \\
$C D$ & 12.08 & 2.19 & 0.1896 \\
$C E$ & 13.62 & 2.47 & 0.1673 \\
$D E$ & 6.83 & 1.24 & 0.3087 \\
Residual & 5.52 & N/A & N/A \\
Lack of fit & 0.49 & 0.084 & 0.9815 \\
Pure error & 10.56 & N/A & N/A \\
\hline Note: $A, B, C D$, & repr
\end{tabular}

Note: $A, B, C, D$, and $E$ represent the fractions of PKOEs, lecithin, Tween 80, glycerol, and water in wt\%, respectively.

Abbreviations: N/A, not applicable; PKOE, Palm kernel oil ester.
Table 4 Regression coefficients of the final reduced model

\begin{tabular}{ll}
\hline Regression coefficient & Value \\
\hline Standard deviation & 2.35 \\
PRESS & 187.00 \\
$R^{2}$ & 0.9957 \\
Adjusted $R^{2}$ & 0.9856 \\
Predicted $R^{2}$ & 0.9756 \\
Adequate precision & 31.944 \\
\hline
\end{tabular}

Abbreviation: PRESS, predicted residual sum of squares.

show that $>90 \%$ of the response variations in the independent variable (droplet size) could be described by mixture design model as a function of the main composition.

So it can be concluded that the quadratic model was a suitable model for analysis and could show the trends very good, the interaction between the parameters was more effective on droplet size of nanoemulsion, and interaction $A C$ (interaction between PKOEs and Tween 80) had the highest effect on response (droplet size) compared with other interactions according to the final mathematical Equation 2.

\section{Response surface analysis}

Figures 2-4 show the three-dimensional surface plots indicating the effects of the interactions between five different components on the droplet size of nanoemulsion. Figure 2 shows that the droplet size value increased toward the higher amounts of oil (PKOEs) where maximum values in droplet size could be seen (red color area); however, the lowest droplet size values of nanoemulsion were observed at higher amounts of lecithin. This is due to a sufficient amount of lecithin available to emulsify the oil and the aqueous phase when the amount of oil was decreased. The plotted model

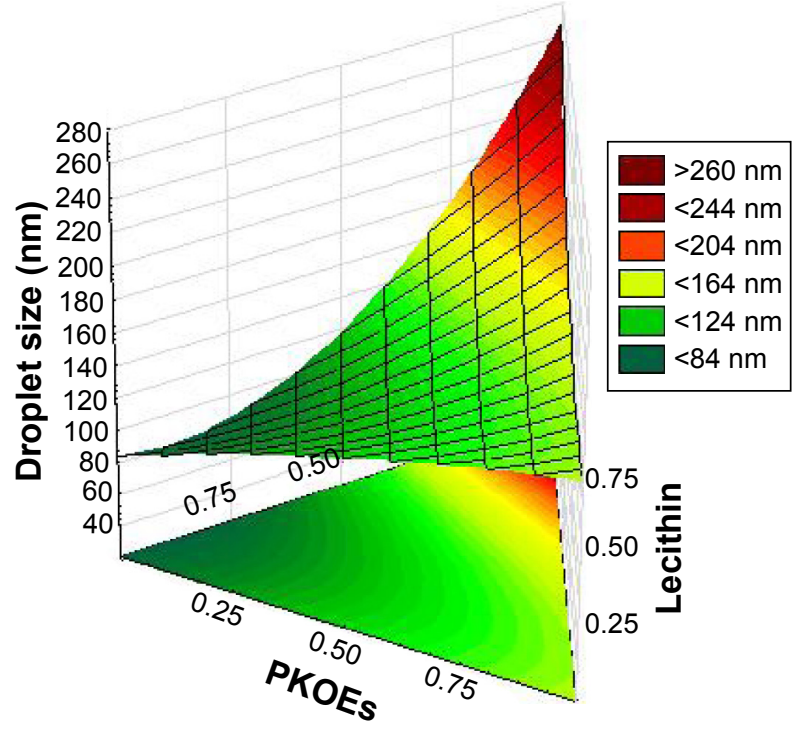

Figure 2 Ternary plots showing the interaction effect between three variables (PKOEs, lecithin, water) on the response (droplet size). Two variables were kept constant (Tween 80 and glycerol).

Abbreviation: PKOE, palm kernel oil ester. 


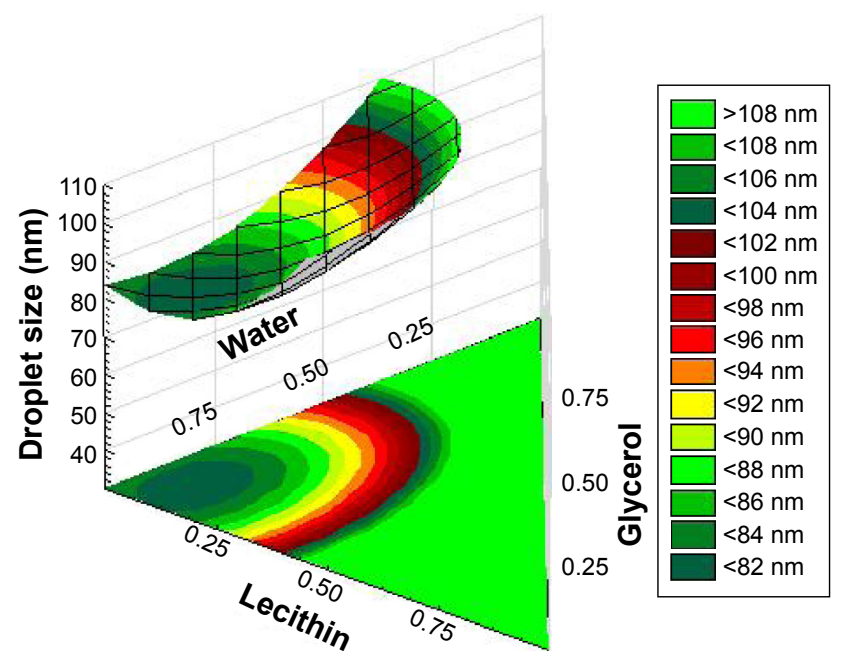

Figure 3 Ternary plots showing the interaction effect between three variables (lecithin, glycerol, water) on the response (droplet size). Two variables were kept constant (PKOEs and Tween 80).

Abbreviation: PKOE, Palm kernel oil ester.

depicted a linear increase in droplet size when the amount of oil was increased.

The increase in the viscosity of the dispersed phase (oil phase) results in increase in the flow resistance, which may result in problems with the droplet disruption process. Thus, the split up rate becomes restricted, causing the large droplets to form. When the amount of lecithin used is decreased, the droplet size of nanoemulsion is increased. This could be due to the fixed amount of the emulsifier (lecithin), leading to incomplete coverage of emulsifier molecules on the newly formed droplets. It is possible that this coverage limitation can lead to an increase in the droplet size of an emulsion. ${ }^{24}$ The pharmaceutical industry demands the production of nanoemulsions with a very small droplet size as it gives extremely low surface tension for the whole system and the interfacial tension of oil-in-water droplets. ${ }^{25}$

Figures 3 and 4 show that the droplet size value decreased toward the higher amounts of glycerol and Tween 80, where minimum values in droplet size could be seen (dark green color area). The observed decrease in droplet diameter with increasing emulsifier concentration can be attributed to various factors: faster emulsifier adsorption to oil droplet

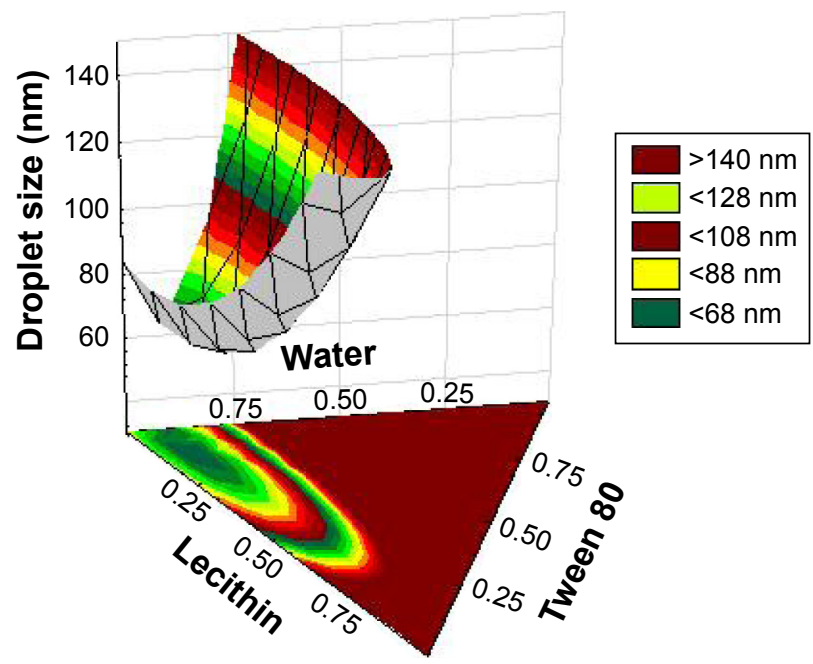

Figure 4 Ternary plots showing the interaction effect between three variables (lecithin, Tween 80 , and water) on the response (droplet size). Two variables were kept constant (PKOEs and glycerol).

Abbreviation: PKOE, Palm kernel oil ester.

surfaces during homogenization leads to lower interfacial tensions thereby facilitating droplet breakup; more emulsifier available to cover the droplet surfaces formed during homogenization. ${ }^{26}$ Increasing amount of emulsifier decreases the interfacial tension, which leads to the reduction in Laplace pressure and stress required for droplet deformation. These results revealed that Tween 80 and lecithin were the components having the highest decreasing effect on the droplet size of nanoemulsions containing aripiprazole.

\section{Verification of models}

Verification of the final model was done to examine the adequacy of the predicted response values in validation set. Five random formulations with the different percentage of components were provided to validate the model. Actual values of the droplet size as a response were compared with the corresponding predicted values to evaluate the validity of the model as shown in Table 5. Percentage of residual standard error was determined for values of formulation result. The results confirmed the adequacy of the model, and the actual values were found to be quite close to the predicted values, which indicated excellent fitness of the model generated.

Table 5 Validation set for five different formulations of nanoemulsion-containing aripiprazole

\begin{tabular}{|c|c|c|c|c|c|c|c|c|}
\hline & \multicolumn{5}{|c|}{ Components } & \multicolumn{3}{|c|}{ Droplet size $(\mathrm{nm})$} \\
\hline & PKOEs (\%) & Lecithin (\%) & Tween 80 (\%) & Glycerol (\%) & Water (\%) & Actual value & Predicted value & RSE (\%) \\
\hline \multirow[t]{5}{*}{ Validation set } & 5.50 & 2.50 & 0.50 & 1.50 & 89.25 & 120.4 & 118.55 & 1.56 \\
\hline & 4.00 & 2.50 & 1.00 & 1.50 & 90.00 & 72.66 & 73.69 & 1.38 \\
\hline & 3.75 & 2.00 & 0.75 & 2.50 & 90.50 & 76.73 & 78.53 & 2.33 \\
\hline & 4.50 & 2.50 & 0.60 & 2.10 & 90.75 & 98.04 & 95.59 & 2.56 \\
\hline & 4.25 & 2.75 & 0.60 & 2.10 & 90.25 & 92.64 & 92.77 & 0.14 \\
\hline
\end{tabular}

Abbreviations: PKOE, palm kernel oil ester; RSE, residual standard error. 
Table 6 Optimum formulation derived by D-optimal mixture experimental design

\begin{tabular}{|c|c|c|c|c|c|c|c|c|}
\hline & \multicolumn{5}{|c|}{ Components } & \multicolumn{3}{|c|}{ Droplet size $(\mathrm{nm})$} \\
\hline & PKOEs (\%) & Lecithin (\%) & Tween 80 (\%) & Glycerol (\%) & Water & Actual value & Predicted value & Desirability \\
\hline $\begin{array}{l}\text { Optimal } \\
\text { formulation }\end{array}$ & 3.00 & 2.00 & 1.00 & 2.25 & 91.75 & 62.23 & 64.24 & 0.963 \\
\hline
\end{tabular}

Abbreviation: PKOE, palm kernel oil ester.

\section{Optimization}

An optimum and stable formulation has the smallest droplet size, the absolute value of $\zeta$-potential of $>30$, and the PDI of $<0.25$. Optimum formulation was obtained based on minimum droplet size of nanoemulsion and optimum Tween 80 amount. Using this approach, a set of components was found. From MED analysis, a composition of 3.0\% PKOEs, $2.0 \%$ lecithin, $1.0 \%$ Tween $80,2.25 \%$ glycerol, and $91.75 \%$ water was predicted that the nanoemulsion would have droplet size, $\zeta$-potential, and PDI of $62.23 \mathrm{~nm},-31.6 \mathrm{mV}$, and 0.18 , respectively. This formulation and predicted result are shown in Table 6. Desirability of optimum formulation was 0.963 . When desirability value was between 0.8 and 1 , the formulation quality was regarded to be acceptable and excellent. When this value was $<0.63$, the formulation quality was regarded as poor. Formulation was considered unacceptable when the desirability value was $<0.37 .^{27}$

\section{Conclusion}

Drugs at the nanosize and larger surface area lead to some very interesting physical properties that can be exploited to overcome anatomical and physiological barriers associated with drug delivery in complex diseases such as schizophrenia. This study showed that encapsulating aripiprazole in nanoemulsions was fabricated by emulsification process through D-optimal experimental design. The initial size of the droplets depended on oil level, emulsifier type, and emulsifier levels, which are the major factors influencing nanoemulsion formation and stability. Nanoemulsion containing small droplets $(d<65 \mathrm{~nm})$ could be formed using $1 \%$ of a nonionic emulsifier (Tween 80 ), lecithin (2\%), glycerol $(2.25 \%)$, and $3 \%$ of PKOEs with constant process parameters during the titration process. In this study, we therefore systematically examined some of the major factors influencing the encapsulation efficiency and stability of nanoemulsions. The nanoemulsion-containing aripiprazole remained physically stable during storage at the temperature of $\pm 5^{\circ} \mathrm{C}$ for 9 months and no precipitations or aggregations were observed, from which it can be concluded that the final nanoemulsion formulation was fabricated with high encapsulation efficiency.

\section{Acknowledgments}

The financial assistance provided by Universiti Putra Malaysia under the Research University Grant Scheme (RUGS) is gratefully acknowledged.

\section{Disclosure}

The authors report no conflicts of interest in this work.

\section{References}

1. Compton WM 3rd, Helzer JE, Hwu HG, et al. New methods in crosscultural psychiatry: psychiatric illness in Taiwan and the United States. Am J Psychiatry. 1991;148(12):1697-1704.

2. Li H, Luo J, Wang C, et al. Efficacy and safety of aripiprazole in Chinese Han schizophrenia subjects: A randomized, double-blind, active parallel-controlled, multicenter clinical trial. Schizophr Res. 2014;157(1-3):112-119.

3. Pigott TA, Carson WH, Saha AR, et al; Aripiprazole Study Group Aripiprazole for the prevention of relapse in stabilized patients with chronic schizophrenia: a placebo-controlled 26-week study. J Clin Psychiatry. 2003;64(9):1048-1056.

4. Potkin SG, Saha AR, Kujawa MJ, et al. Aripiprazole, an antipsychotic with a novel mechanism of action, and risperidone vs placebo in patients with schizophrenia and schizoaffective disorder. Arch Gen Psychiatry. 2003;60:681-690.

5. McEvoy JP, Daniel DG, Carson WH Jr, McQuade RD, Marcus RN. A randomized, double-blind, placebo-controlled, study of the efficacy and safety of aripiprazole 10,15 or $20 \mathrm{mg} /$ day for the treatment of patients with acute exacerbations of schizophrenia. J Psychiatr Res. 2007;41:895-905.

6. Chan HY, Lin WW, Lin SK, et al. Efficacy and safety of aripiprazole in the acute treatment of schizophrenia in Chinese patients with risperidone as an active control: a randomized trial. J Clin Psychiatry. 2007;68: 29-36.

7. Mailman RB, Murthy V. Third generation antipsychotic drugs: partial agonism or receptor functional selectivity? Curr Pharm Des. 2010;16: 488.

8. Wood M, Reavill C. Aripiprazole acts as a selective dopamine D2 receptor partial agonist. Expert Opin Investig Drugs. 2007;16(6):771-775.

9. Stip E, Tourjman V. Aripiprazole in schizophrenia and schizoaffective disorder: a review. Clin Ther. 2010;32:S3-S20.

10. Bhattacharjee J, El-Sayeh H. Aripiprazole versus typical antipsychotic drugs for schizophrenia. Cochrane Database Syst Rev. 2008;3: CD006617.

11. Gaboriau L, Victorri-Vigneau C, Gérardin M, Allain-Veyrac G, JollietEvin P, Grall-Bronnec M. Aripiprazole: a new risk factor for pathological gambling? A report of 8 case reports. Addict Behav. 2014;39: $562-565$.

12. Merisko-Liversidge E, Liversidge GG. Nanosizing for oral and parenteral drug delivery: a perspective on formulating poorly-water soluble compounds using wet media milling technology. Adv Drug Deliv Rev. 2011;63:427-440

13. Woo FY, Basri M, Masoumi HRF, Ahmad MB, Ismail M. Formulation optimization of galantamine hydrobromide loaded gel drug reservoirs in transdermal patch for Alzheimer's disease. Int J Nanomedicine. $2015 ; 10: 3879$. 
14. Musa SH, Basri M, Masoumi HR, et al. Formulation optimization of palm kernel oil esters nanoemulsion-loaded with chloramphenicol suitable for meningitis treatment. Colloids Surf B Biointerfaces. 2013;112:113-119.

15. Ngan CL, Basri M, Lye FF, et al. Comparison of process parameter optimization using different designs in nanoemulsion-based formulation for transdermal delivery of fullerene. Int J Nanomedicine. 2014;9: 4375 .

16. Kamairudin N, Gani SSA, Masoumi HRF, Hashim P. Optimization of natural lipstick formulation based on pitaya (Hylocereus polyrhizus) seed oil using D-optimal mixture experimental design. Molecules. 2014; 19:16672-16683.

17. Seabra I, Braga M, de Sousa H. Statistical mixture design investigation of CO 2-ethanol-H 2 O pressurized solvent extractions from tara seed coat. J Supercrit Fluids. 2012;64:9-18.

18. Keng P, Basri M, Zakaria M, Rahman M, Ariff A, et al. Newly synthesized palm esters for cosmetics industry. Ind Crop Prod. 2009;29: 37-44.

19. Kamoun A, Chaabouni M, Sergent M, Phan-Tan-Luu R. Mixture design applied to the formulation of hydrotropes for liquid detergents. Chemometr Intell Lab. 2002;63:69-79.
20. Rahali Y, Pensé-Lhéritier AM, Mielcarek C, Bensouda Y. Optimization of preservatives in a topical formulation using experimental design. Int J Cosmet Sci. 2009;31:451-460.

21. Krol S. Challenges in drug delivery to the brain: nature is against us. J Control Release. 2012;164:145-155.

22. Floyd AG. Top ten considerations in the development of parenteral emulsions. Pharm Sci Technolo Today. 1999;2:134-143.

23. Song J, Shi F, Zhang Z, et al. Formulation and evaluation of celastrolloaded liposomes. Molecules. 2011;16:7880-7892.

24. Jafari SM, He Y, Bhandari B. Effectiveness of encapsulating biopolymers to produce sub-micron emulsions by high energy emulsification techniques. Food Res Int. 2007;40:862-873.

25. Tang SY, Manickam S, Wei TK, Nashiru B. Formulation development and optimization of a novel Cremophore EL-based nanoemulsion using ultrasound cavitation. Ultrason Sonochem. 2012;19:330-345.

26. Ozturk B, Argin S, Ozilgen M, McClements DJ. Formation and stabilization of nanoemulsion-based vitamin E delivery systems using natural biopolymers: Whey protein isolate and gum Arabic. Food Chem. 2015;188:256-263.

27. Lazic Z. Design of Experiments in Chemical Engineering: A Practical Guide. Weinheim, Germany: Wiley-VCH; 2004.
International Journal of Nanomedicine

\section{Publish your work in this journal}

The International Journal of Nanomedicine is an international, peerreviewed journal focusing on the application of nanotechnology in diagnostics, therapeutics, and drug delivery systems throughout the biomedical field. This journal is indexed on PubMed Central, MedLine, CAS, SciSearch ${ }^{\circledR}$, Current Contents ${ }^{\circledR} /$ Clinical Medicine,

\section{Dovepress}

Journal Citation Reports/Science Edition, EMBase, Scopus and the Elsevier Bibliographic databases. The manuscript management system is completely online and includes a very quick and fair peer-review system, which is all easy to use. Visit http://www.dovepress.com/ testimonials.php to read real quotes from published authors. 